Research Paper

\title{
Low-intensity pulsed ultrasound promotes Schwann cell viability and proliferation via the GSK-3 $\beta / \beta$-catenin signaling pathway
}

Cong Ren 1 , Xiaohui Chen², Ning Du², Shuo Geng², Yingying $\mathrm{Hu}^{4}$, Xin $\mathrm{Liu}^{2}$, Xianxian $\mathrm{Wu}^{2}$, Yuan Lin², Xue Bai $^{2}$, Wenzhe Yin ${ }^{1}$, Shi Cheng ${ }^{1}$, Lei Yang ${ }^{3 凶}$, Yong Zhang ${ }^{2,5 \bowtie}$

1. Department of Orthopedics, The Second Affiliated Hospital of Harbin Medical University, Harbin, Heilongiiang Province 150086, China.

2. Departmentof Pharmacology (the State-Province Key Laboratories of Biomedicine-Pharmaceutics of China), Harbin Medical University, Harbin, eilongiang Province 150081, China.

3. Department of Orthopedics, The First Affiliated Hospital of Harbin Medical University, Harbin, Heilongjiang Province 150001, China.

4. Department of Pharmacy, The First Affiliated Hospital of Harbin Medical University, Harbin 150001, China.

5. Institute of Metabolic Disease, Heilongjiang Academy of Medical Science, Harbin, Heilongiiang Province 150086, China.

$\triangle$ Corresponding authors: Lei Yang or Yong Zhang, Department of Orthopedics, The First Affiliated Hospital of Harbin Medical University, No. 23 Post Street, Nangang District, Harbin 150001, China, E-mail: yangray83@vip.qq.com; Department of Pharmacology, Harbin Medical University, 157 Baojian Road, Nangang District, Harbin, Heilongjiang Province, China, 150081, E-mail: hmuzhangyong@hotmail.com

(c) Ivyspring International Publisher. This is an open access article distributed under the terms of the Creative Commons Attribution (CC BY-NC) license (https://creativecommons.org/licenses/by-nc/4.0/). See http://ivyspring.com/terms for full terms and conditions.

Received: 2017.08.16; Accepted: 2018.02.16; Published: 2018.04.05

\begin{abstract}
Background: It has been reported that ultrasound enhances peripheral nerve regeneration, but the mechanism remains elusive. Low-intensity pulsed ultrasound (LIPUS) has been reported to enhance proliferation and alter protein production in various types of cells. In this study, we detected the effects of LIPUS on Schwann cells.

Material and methods: Schwann cells were separated from new natal Sprague-Dawley rat sciatic nerves and were cultured and purified. The Schwann cells were treated by LIPUS for 10 minutes every day, with an intensity of $27.37 \mathrm{~mW} / \mathrm{cm}^{2}$. After treatment for 5 days, MTT, EdU staining, and flow cytometry were performed to examine cell viability and proliferation. Neurotrophic factors, including FGF, NGF, BDNF, and GDNF, were measured by western blot and real-time PCR. GSK-3 $\beta, P-G S K-3 \beta, \beta$-catenin and Cyclin DI protein levels were detected using a western blot analysis. The expression of Cyclin DI was also detected by immunofluorescence.

Results: MTT and EdU staining showed that LIPUS increased the Schwann cells viability and proliferation. Compared to the control group, LIPUS increased the expression of growth factors and neurotrophic factors, including FGF, NGF, BDNF, GDNF, and Cyclin D1. Meanwhile, GSK-3ß activity was inhibited in the LIPUS group as demonstrated by the increased level of $p-G S K-3 \beta$ and the ratio of the $p$-GSK-3 $\beta / G S K-3 \beta$ level. The mRNA and protein expressions of $\beta$-catenin were increased in the LIPUS group. However, SB216763, a GSK-3 $\beta$ inhibitor, reversed the effects of LIPUS on Schwann cells.
\end{abstract}

Conclusion: LIPUS promotes Schwann cell viability and proliferation by increasing Cyclin DI expression via enhancing the GSK-3 $\beta / \beta$-catenin signaling pathway.

Key words: Schwann cell, Low-intensity pulsed ultrasound, Cyclin D1, GSK-3 $\beta$ / $\beta$-catenin signaling pathway

\section{Introduction}

Peripheral nerve injury is common in the clinic and often leaves pain or other motor and sensory nerve defects[1]. The connection between the nerve fiber and the distal organ can be negatively affected or lost, and for some clinical patients, the distal organ undergoes atrophy. Its recovery is always incomplete, often costs too much and leaves personal hardship[2]. In the past decades, minimally invasive surgery was 
widely applied in the clinic, but peripheral nerve injury has still seen no significant improvement[3]. In the process of peripheral nerve repair and regeneration, Schwann cells are crucial factors that clear up cell residue due to their phagocytic function, providing neurons with nutritional factors and suitable space[4]. Recently, Schwann cells were recognized in the repair of the peripheral nerve system, including cell migration, viability, proliferation, and nutritional factor secretion activity[5]. Thus, it is very important and crucial to improve the biofunction of Schwann cells.

Ultrasound has been widely used in the clinic for decades and is acknowledged as harmless. Some studies reveal that ultrasound accelerates injured tissue regeneration or repair, such as bone fracture and tendon healing[6]. In the biological fields, ultrasound is also widely used in many in vitro studies and is known to enhance cell proliferation or alter protein expression in various types of cells, such as endothelial cells, osteoblasts, chondrocytes, and fibroblasts[7-9]. To date, even though many ultrasound-related proteins have been reported using in vitro studies[10], the mechanism of its biological effect is largely unknown.

Low-intensity pulsed ultrasound (LIPUS) sends mechanical energy to the biological tissue in the form of pressure wave propagation to the micro-pressure as a medical diagnosis and treatment tool. LIPUS has been applied to promote fracture healing and callus formation in the treatment of fractures. As a mechanical stimulation, it improves chondrocytes proliferation and survival[11, 12], accelerates fracture healing[13], and promotes bone maturation in clinical distraction osteogenesis cases[14]. LIPUS establishes a mechanical strain, which stimulates the callus healing and periosteal bone formation. At present, the application of LIPUS is still controversial. The intensity and time of LIPUS and its side effects in clinical application do not have enough research for its support. Many studies focus on Schwann cells to examine the effect of LIPUS on nerve regeneration. However, the recovery of injured nerve is generally poor.

When the peripheral nerve is cut or crushed, there are many stress reactions, such as changes in the neurotrophic factors, cytokines, adhesion molecules and growth-promoting molecules. The neurotrophic factor expression is related to the reaction and viability of the Schwann cells to attenuate the damage. Cyclins are regulatory subunits of CDKs (Cyclin-dependent kinases) that control the cells throughout the cell cycle, with their protein levels change periodically as an adapting requirement. During the regeneration process, Schwann cells dedifferentiate, reenter the cell cycle (controlled by the Cyclin/CDK complexes) and increase several-fold in number in the distal stump. We used an EdU (5-Ethynyl-2'-deoxyuridine) staining method to study Schwann cell proliferation after irradiation by LIPUS and examined the GSK-3 $\beta / \beta$-catenin/Cyclin D1 pathway to study the possible mechanism.

GSK-3 $\beta$ (Glycogen synthase kinase-3 $\beta$ ), a cytoplasmic serine/threonine protein kinase, plays a central role in a number of important development signaling pathways. GSK- $3 \beta$ regulates Cyclin D1 gene transcription by the phosphorylation of $\beta$-catenin[15]. We pay particular attention to GSK-3 $\beta$, with reference to Cyclin D1, because this serine/threonine protein kinase regulates Cyclin D1 gene transcription by the phosphorylation of $\beta$-catenin[15].

Based on the above findings, we investigated whether LIPUS promotes Schwann cell viability and proliferation and examined whether the GSK-3 $\beta$ / $\beta$-catenin/Cyclin D1 signaling pathway is the possible mechanism.

\section{Materials and methods}

\section{Ethics statement}

All the experimental procedures were approved by the Animal Care and Ethic Committee and Use Committee of Harbin Medical University (HMUIRB-2008-06), and complied with the Guide for the Care and Use of Laboratory Animals published by the US National Institutes of Health (NIH Publication No. 85-23, revised 1996).

\section{Cell culture and purification}

Schwann cells were extracted from the sciatic nerve of postnatal 1-3 days' Sprague-Dawley rats[16]. All the neonatal male Sprague-Dawley rats were obtained from the Second Affiliated Hospital of Harbin Medical University. Both sides of neonatal rats' sciatic nerve were removed and then were cut into 2-3 $\mathrm{mm}$ small broken pieces. The nerve pieces were mixed with $0.25 \%$ trypsin for shaking digestion in a $37^{\circ} \mathrm{C}$ water bath for $10 \mathrm{~min}$ and were mixed thoroughly with $10 \%$ fetal serum culture DMEM to terminate the digestion. The mixture was centrifuged at 1000 revolutions per minute for $5 \mathrm{~min}$, and then, the supernatant was discarded and $10 \%$ serum culture medium was added. The cells were plated on the culture flasks and were allowed to adhere for 2 days at $37^{\circ} \mathrm{C}$. Under the microscope, we observed that cells adhered to the bottom, and then, we digested the cells with trypsin.

\section{LIPUS treatment}

Schwann cells were plated onto 6-well plates at an initial density of $2 \times 10^{4}$ per well. We divided them 
into two groups as follows: the control group (Schwann cells without LIPUS treatment) and the ultrasound group (Schwann cells with LIPUS treatment at $27.25 \mathrm{~W} / \mathrm{cm}^{2}$ for $10 \mathrm{~min}$ once a day, which lasted 5 days). The transducer was $75 \%$ ethanol, and the culture plates were put on the transducer.

\section{3-(4,5-dimethyl-2-thiazolyl)-2,5-diphenyl-2-H-t etrazolium bromide (MTT) assay}

Schwann cells were plated onto 96-well plates at a density of $1 \times 10^{3}$ cells per well. When the cells were treated with LIPUS for 5 days, we added $20 \mu \mathrm{l}$ of a $0.5 \%$ MTT solution, and the cells were incubated for 4 $\mathrm{h}$. Then, the culture solution was discarded, and the Schwann cells were washed 3 times with PBS. We added $150 \mu \mathrm{l}$ of Dimethyl Sulfoxide in to every well and put the plates on rocking bed that oscillated for 10 min at low speed. The absorbance value was detected on the enzyme-linked immune detector at $490 \mathrm{~nm}[17]$.

\section{Cell proliferation assay}

Schwann cell proliferation was detected using the EdU staining kit and flow cytometry. EdU, as a thymidine analogue, inserts into DNA molecules during replication. Based on the EdU and dye conjugation reaction, EdU staining effectively detects the percentage of cells in the $S$ phase and detects cell proliferation efficiently and rapidly. After the Schwann cells were treated with LIPUS for 5 days, we added $25 \mu \mathrm{M}$ 5-Ethynyl-2'-deoxyuridine into the well and co-incubated with serum free DMEM. The Schwann cells were rinsed with a phosphate buffer solution for $5 \mathrm{~min}$, and this was repeated twice. Then, they were immobilized with $4 \%$ paraformaldehyde for $30 \mathrm{~min}$. The Schwann cells were treated with glycine for $5 \mathrm{~min}$ and rinsed with PBS for $5 \mathrm{~min}$. The Schwann cells were treated with the Apollo staining solution EdU staining kit for $30 \mathrm{~min}$ and were treated with 4,6-diamidino-2-phenylindole staining for 15 min. Lastly, the Schwann cells were rinsed with PBS 3 times. We observed the cells using a fluorescence microscope in 5 horizons.

\section{Flow cytometry}

After the Schwann cells were treated with LIPUS for 5 days, the Schwann cells were harvested and washed twice with PBS. Then, we fixed the cells with $75 \%$ cold ethanol for $30 \mathrm{~min}$. We retreated the cells with PBS and stained the cells with PI for $30 \mathrm{~min}$. Finally, the cells were analyzed for cell cycle detection by an automatic flow cytometry FACS Calibur.

\section{Real-time PCR}

The Schwann cells were seeded in 6-well plates and were treated with LIPUS for 5 days. Total RNA was extracted using the Trizol reagent, and its concentration was determined spectrophotometrically at $260 \mathrm{~nm}$ with a purity of an A260/A280 ratio that ranged from 1.8 to 2.1[18]. We obtained the cDNA according to reverse transcription using the Fast Quant RT Kit manufacturer's protocol. Real-time PCR (Polymerase Chain Reaction) was performed using the SYBR Green PCR Master Mix Kit on a 7500 FAST real-time PCR system for 40 cycles, with GAPDH as the internal control[19]. The primers used in the study are provided in Table 1.

Table 1. Nucleotide sequence of primers for real-time PCR.

\begin{tabular}{lll}
\hline Gene & Primer Sequence & \\
\hline FGF & Forward & 5'-GACACGTGCCTTACAGCCTC-3' \\
& Reverse & 5'-TGGTCTGACTTTGACCCTTGG-3' \\
NGF & Forward & 5'-TGAACCAATAGCTGCCCGTG-3' \\
& Reverse & 5'-GTGGAGGCTGGGTGCTAAA-3' \\
BDNF & Forward & 5'-TTCGAGAGGTCTGACGACGA-3' \\
& Reverse & 5'-AGTCCGCGTCCTTATGGTTT-3' \\
GDNF & Forward & 5'-GTCACCAGATAAACAAGCGGC-3' \\
& Reverse & 5'-CCCTCTGGAATTCTCTGGGC-3' \\
Cyclin D1 & Forward & 5'-AGCTGTGCATCTACACCGAC-3' \\
& Reverse & 5'-TGTGAGGCGGTAGTAGGACA-3' \\
GAPDH & Forward & 5'-AAGAAGGTGGTGAAGCAGGC-3' \\
& Reverse & 5'-TCCACCACCCAGTTGCTGTA-3' \\
\hline
\end{tabular}

\section{Immunofluorescence staining}

The cultured neonatal Schwann cells were fixed with $4 \%$ paraformaldehyde dissolved in PBS. The cells were penetrated and incubated for $2 \mathrm{~h}$ by a blocking solution, including $1 \%$ BSA and $0.1 \%$ Triton- $X$ in PBS. The cells were incubated with the primary antibodies, including Cyclin D1 and S100 (Schwann marker), overnight at $4^{\circ} \mathrm{C}[20]$. The following day, the cells were incubated with the appropriate secondary antibody for $1 \mathrm{~h}$ at room temperature. The nuclei were stained for $20 \mathrm{~min}$ at room temperature. Finally, we detected the cells under a fluorescence microscope.

\section{Western blot}

After LIPUS treatment, the Schwann cells were lysed with $80 \mu \mathrm{l}$ of lysis buffer per well on ice containing $50 \mathrm{mM}$ Tris-base, $150 \mathrm{mM} \mathrm{NaCl}, 1 \mathrm{mM}$ EDTA, $1 \mathrm{mM}$ sodium orthovanadate, $20 \mathrm{mM} \mathrm{NaF}, 1 \%$ Triton X-100, $0.1 \%$ SDS, $1 \%$ sodium deoxycholate, $\mathrm{pH}$ 7.4 , and $1 \%$ protease inhibitors. The protein concentration was determined by the BCA protein assay kit[21]. Equal amounts of protein samples were separated by $10 \%$ SDS-PAGE and were transferred onto nitrocellulose membranes[22]. After blocking with $5 \%$ non-fat milk, the membranes were incubated with primary antibodies against GSK-3 $\beta$, p-GSK-3 $\beta$, FGF, NGF, BDNF, GDNF and $\beta$-catenin (Abcam, Cambridge, MA, USA), Cyclin D1 and GAPDH, 
diluted at 1:500 in PBS buffer, overnight at $4^{\circ} \mathrm{C}$. The membranes were washed in the PBS with $0.05 \%$ Tween 20 and were incubated with a fluorescence-conjugated anti-rabbit IgG secondary antibody (1:10000) for $1 \mathrm{~h}[23]$. After the incubation with the secondary antibody, the protein bands were quantified using Odyssey v1.2 software, and we measured with the target band intensity compared to GAPDH[24].

\section{Data analysis}

All the data are presented as the mean \pm SEM, and multiple comparisons were analyzed with one-way analysis of variance (ANOVA) by GraphPad Prism 5.0. $\quad \mathrm{P}<0.05$ was considered statistically significant.

\section{Results}

\section{Effect of LIPUS on Schwann cell viability}

S100 is the special marker of Schwann cells. The purity of the Schwann cells was more than 95\% (Figure 1A). The ultrasound transmitter was refitted by the Chinese Academy of Science, Institute of Acoustics Research Station, including 20 grades, and its electric power ranged from 6-30 $\mathrm{W}$ accompanied by an ultrasound power of $7.2 \sim 89.0 \mathrm{~W} / \mathrm{cm}^{2}$. To get the optimal ultrasound intensity, we chose grades 3, 5, 7, 8,9 , and 10, and their ultrasound intensity were, respectively, $9.0 \mathrm{~W} / \mathrm{cm}^{2}, 16.0 \mathrm{~W} / \mathrm{cm}^{2}, 23.0 \mathrm{~W} / \mathrm{cm}^{2}$, $27.5 \mathrm{~W} / \mathrm{cm}^{2}, 32.5 \mathrm{~W} / \mathrm{cm}^{2}, 35.0 \mathrm{~W} / \mathrm{cm}^{2}$, and 40.0 $\mathrm{W} / \mathrm{cm}^{2}$. The results showed that an ultrasound intensity of $27.5 \mathrm{~W} / \mathrm{cm}^{2}$ and $32.5 \mathrm{~W} / \mathrm{cm}^{2}$ increased the OD value significantly compared with the control group $\left(0 \mathrm{~W} / \mathrm{cm}^{2}\right)$ (Figure $\left.1 \mathrm{~B}\right)$. The $27.5 \mathrm{~W} / \mathrm{cm}^{2}$ ultrasound intensity optimally promoted cell viability, and thus, the subsequent experiments used this intensity as the ultrasound group. In Figure 1C, the cells were treated for $10 \mathrm{~min}$ per day for 5 days. The viability of the Schwann cells increased compared with the non-LIPUS treated group.

\section{Effects of LIPUS on secreting growth factors and neurotrophic factors}

To observe the biofunction of LIPUS on the Schwann cells, we detected the expression of growth factors and neurotrophic factors. There are four important factors that have crucial functions in Schwann cell activity, including FGF, NGF, BDNF, and GDNF. NGF directly regulates the structure via targeting the proteins that comprise myelin[25], and FGF enhances the efficacy of Schwann cells. BDNF and GDNF regenerate axons after immediate nerve repair[26]. After the cells were treated with LIPUS, the protein and mRNA levels of FGF, NGF, BDNF and GDNF increased significantly compared with the control group (Figure 2A-2H).

A
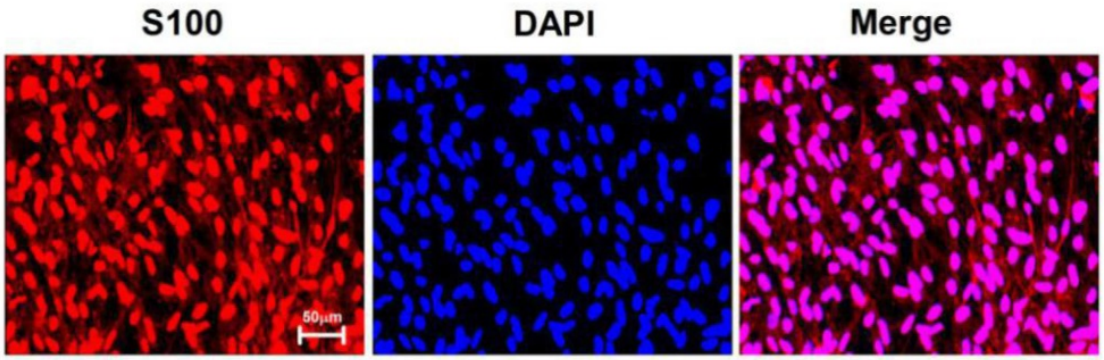

B

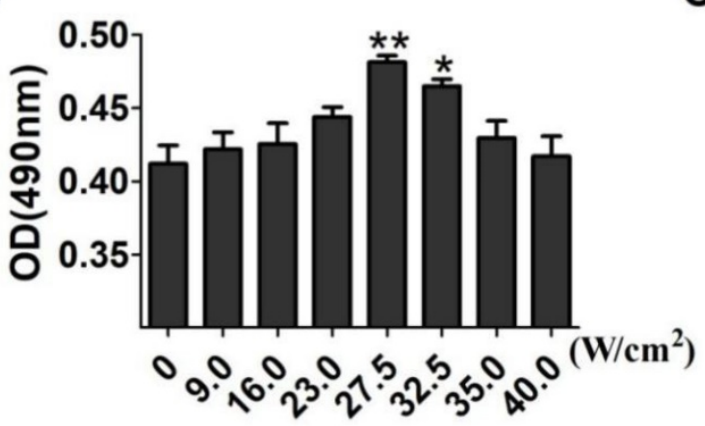

C

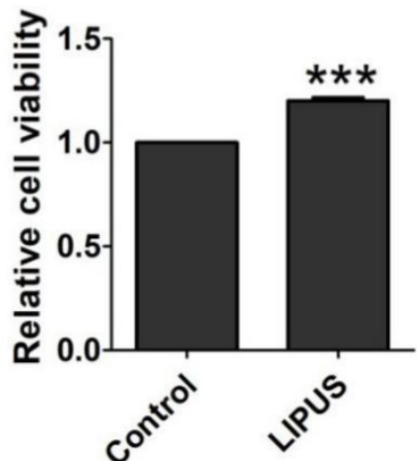

Figure 1. Effect of LIPUS on Schwann cell viability. (A). The purity of the extracted Schwann cells was detected by immunostaining for S100 ( $\times 200)$. (B). Determination of the optimal low energy pulse intensity. The Schwann cells were treated with $9.0,16.0,23.0,27.5,32.5,35.0$, and $40.0 \mathrm{~W} / \mathrm{cm}^{2}$ and were assessed by MTT. **p $<0.01$ vs $0 \mathrm{~W} / \mathrm{cm}^{2}$, *p $<0.05 ;$ mean \pm SEM. $\mathrm{n}=4$. (C). The cell viability was detected with the MTT assay. ***p $<0.001$ vs Control; mean \pm SEM. $\mathrm{n}=4$. 
A

FGF-2 GAPDH $\longrightarrow$

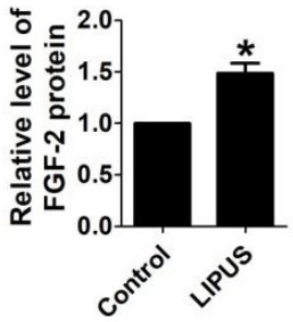

B

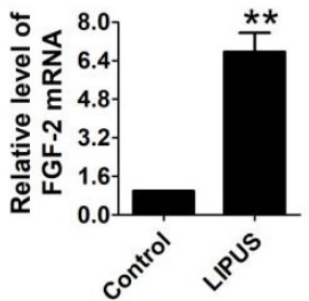

C
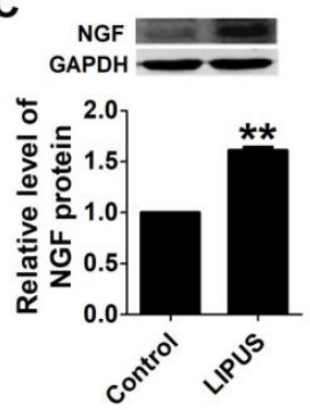

D

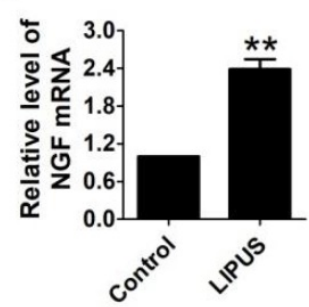

E
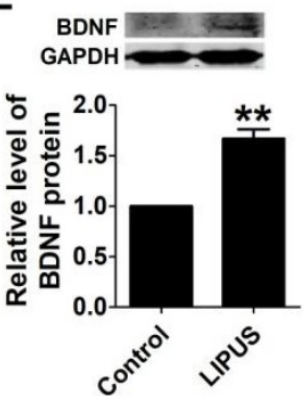

$\mathbf{F}$

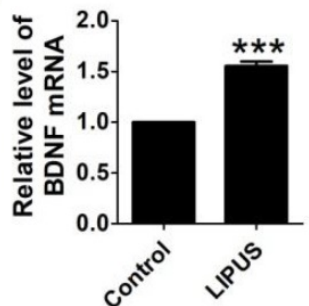

G

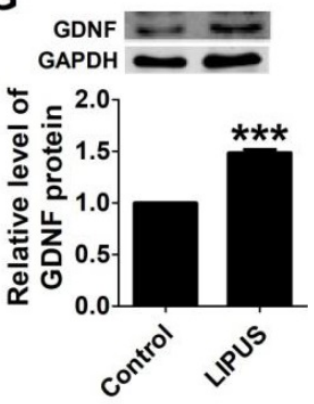

H

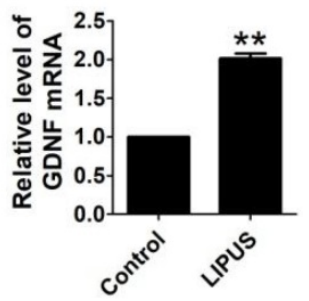

Figure 2. Effects of LIPUS on the Schwann cell-secreted growth factors and neurotrophic factors. (A-D). The protein and mRNA expressions of the growth factors (FGF, NGF) were detected by western blot and real-time PCR in the control and ultrasound groups. (E-H). Neurotrophic factor (BDNF, GDNF) protein and mRNA expression were detected by western blot and real-time PCR in the control and ultrasound groups. ***p $<0.001$ vs Control, **p $<0.01$; mean \pm SEM. $n=3-5$.

\section{Effects of LIPUS on Schwann cell proliferation}

Cell proliferation was detected with EdU staining. The Ultrasound group was treated by $1 \mathrm{MHz}$ LIPUS with $27.5 \mathrm{~W} / \mathrm{cm}^{2}$. Our data showed that there was more 5-Bromo-2-deoxyuridine participating in

A

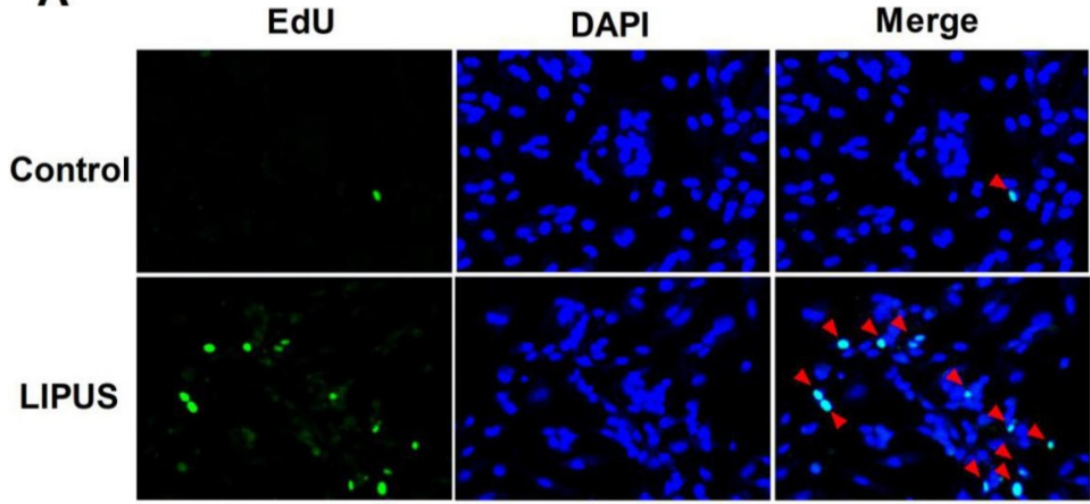

B

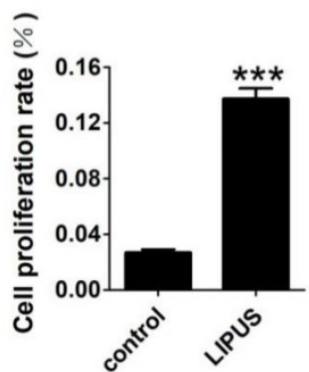

Figure 3. Effects of LIPUS on the Schwann cells proliferation. (A). The cell proliferation was detected with EdU staining $(\times 200)$. (B). The statistical data of the EdU staining. ${ }^{* * *} p<0.001$ vs Control; mean \pm SEM. $n=5$.
DNA replication in the LIPUS group (Figure 3A). The statistical data showed that LIPUS significantly stimulated Schwann cell proliferation (Figure 3B).

\section{Effects of LIPUS on Cyclin DI expression}

To further explore the molecular mechanism of LIPUS on cell proliferation, we found that the protein and mRNA level of Cyclin D1 in LIPUS group was significantly increased (Figure 4A and 4B). The immunostaining figure also showed that there was more Cyclin D1 expressed in the Schwann cells (Figure 4C).

\section{LIPUS promotes Schwann cell viability and proliferation via the GSK-3 $\beta / \beta$-catenin signaling pathway}

Previous studies indicate that the GSK- $3 \beta / \beta$-catenin signaling pathway regulates the expression of Cyclin D1. In our study, the GSK-3 $\beta$ activity was inhibited in the LIPUS group as demonstrated by the increased level of $p$-GSK-3 $\beta$ (serine-9 phosphorylation) and the ratio of the p-GSK-3 $\beta /$ GSK-3 $\beta$ level (Figure 5A-5C). Meanwhile, the mRNA and protein expression of $\beta$-catenin increased in the LIPUS group (Figure 
5D and 5E). Thus, the LIPUS enhanced Schwann cell proliferation by activating the GSK- $3 \beta / \beta$-catenin pathway. The data showed that the expression of
p-GSK-3 $\beta$, GSK-3 $\beta, \beta$-catenin and Cyclin D1 were restored by co-treating with SB216763, a GSK-3 $\beta$ inhibitor (Figure 5A-5G).
A
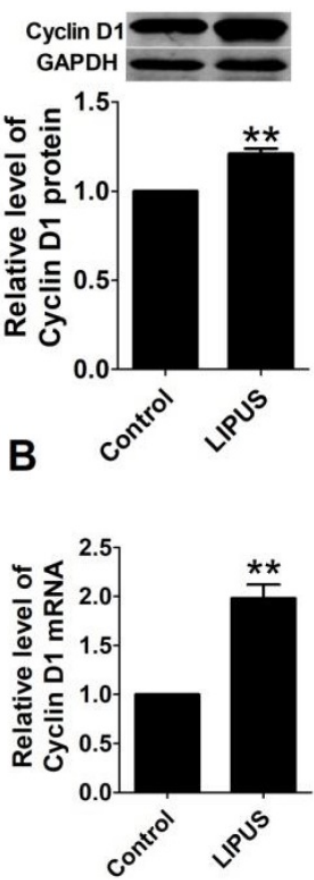

C

Control

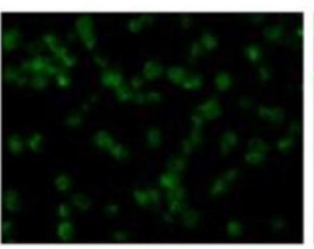

DAPI

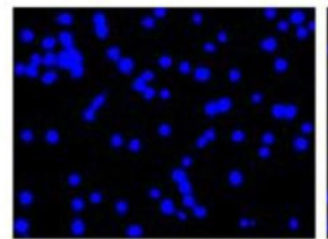

Merge

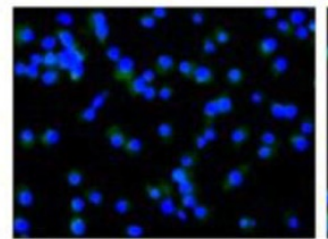

LIPUS
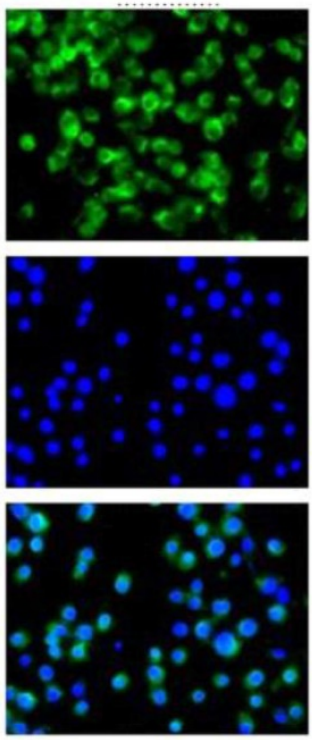

Figure 4. Effects of LIPUS on the expression of Cyclin D1. (A). Cyclin D1 expression measured by the western blot in the control, and ultrasound groups. (B). Cyclin DI mRNA expression detected by real-time PCR in the control, and ultrasound groups. $* *<<0.01$ vs Control; mean \pm SEM. $n=5$. (C). The immunostaining of Cyclin D1 $(\times 200)$.

A

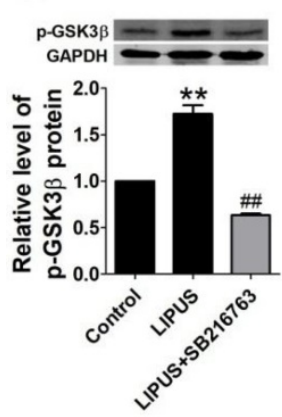

D

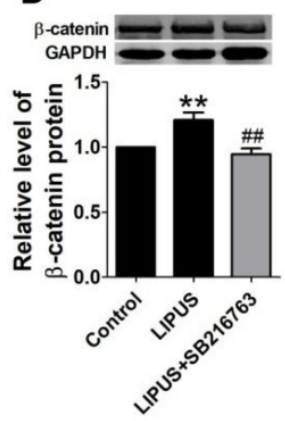

B

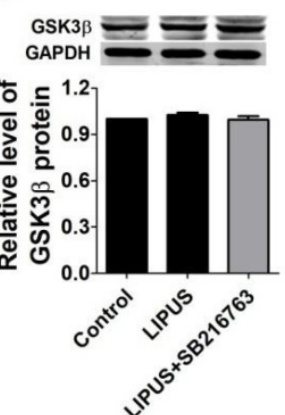

E

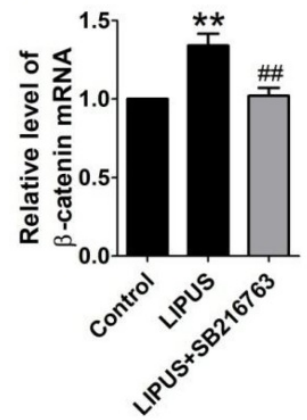

C

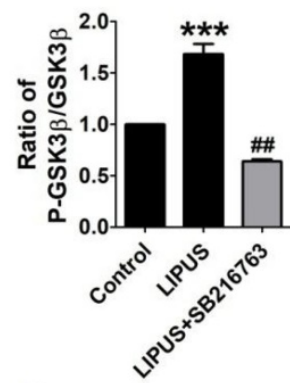

$\mathbf{F}$

G

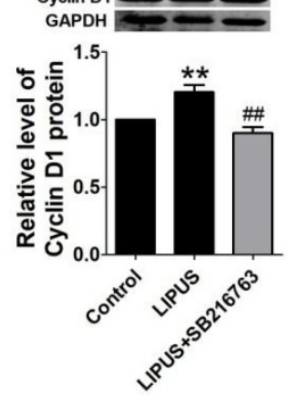

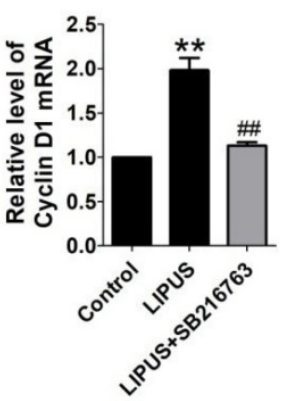

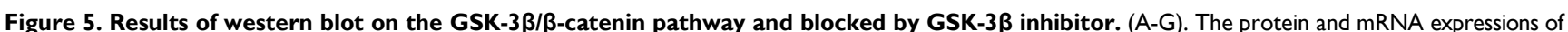
P-GSK-3 $\beta$, GSK-3 $\beta$ and Cyclin DI were detected by western blot and real-time PCR in the control ultrasound group. ** $<<0.01$ vs Control, \#\# $<<0.01$ vs LIPUS; mean \pm SEM. $n=4-5$. 
The immunofluorescence staining of Cyclin D1 and the EdU staining also showed the SB216763 reversed the effects of LIPUS (Figure 6A and 6B). The results showed that the GSK-3 $\beta$ inhibitor reversed the effects of LIPUS on Schwann cells (Figure 7A). We further detected the cell viability by flow cytometry, and the results showed that LIPUS increased the amount and percentage of cells in $\mathrm{S}$ phase (Figure 7B and 7C).

We inhibited $\beta$-catenin (by siRNA) and co-treated with the LIPUS. The data showed that the expression of Cyclin D1 was restored (Figure 8A and $8 \mathrm{~B})$. We detected the cell viability with MTT. The results showed that $\beta$-catenin inhibition reversed the function of LIPUS (Figure 8C). We also detected the cell proliferation after co-treated with LIPUS and $\beta$-catenin inhibition, and the results showed that $\beta$-catenin inhibition reversed the function of LIPUS (Figure 8D and 8E).

\section{Discussion}

Peripheral nerve injury is divided into two types[27]. One type is axonotmesis, with basal lamina tubes that remain intact with axons that are disrupted.

A

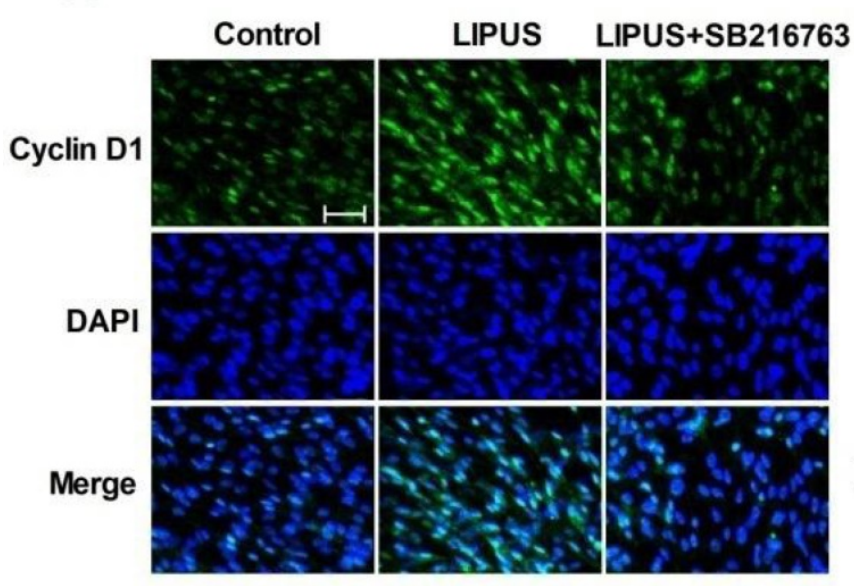

B

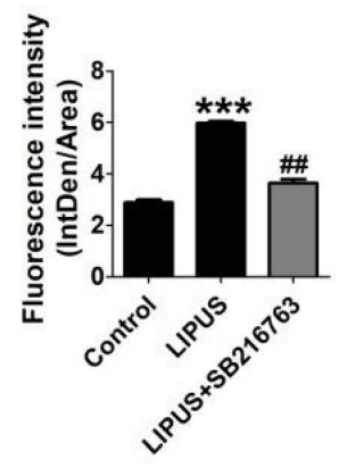

In this type, the regeneration of axons is remarkable and nerve function is restored in 3-4 weeks. Another type is neurotmesis, in which all the tissue is disrupted. In this type, function is partly restored when the two ends of the nerve are reconnected by a newly formed tissue bridge. Regeneration units, formed by axons and Schwann cells, though this bridge grow to the distal stump of the injured nerve[28, 29]. Ultrasound is effective in both types of peripheral nerve injury[1, 2, 30-35], which indicates that ultrasound may be useful in two methods or more to improve peripheral nerve regeneration.

In both types of peripheral nerve injury, Schwann cells play an important role. After nerve injury, Wallerian degeneration contributes an environment that helps to support the survival of the injured neurons and promote nerve regeneration. Axon regrowth and guidance are supported by Schwann cells[36-38]. Schwann cells up-regulate a group of neurotrophic factors (GDNF, artemin, BDNF, NT3, NGF, VEGF, etc.) $[39,40]$ and up-regulate the expression of the cytokines tumor necrosis factor (TNF)-a, LIF, interleukin (IL)-1a, IL-1b, LIF, and MCP-1[41-43].

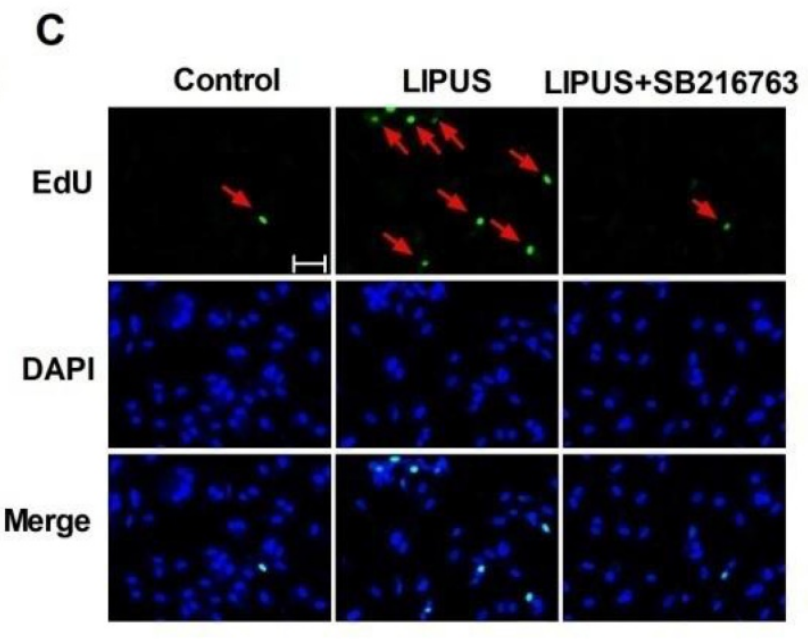

D

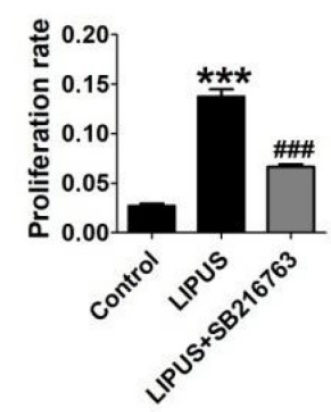

Figure 6. Effects on the expression of Cyclin D1 by inhibitor SB216763. (A). The immunofluorescence staining of Cyclin D1 ( $\times 200)$. (B). Quantification of the Cyclin D1 fluorescence intensity. $n=3$. (C). EdU staining of the control, ultrasound and inhibitor SB216763 ( $\times 200)$. (D). The statistical data of the EdU staining. **** $\mathrm{p}<0.001$ vs Control, ${ }^{m} \mathrm{p}<0.01$ vs LIPUS; mean \pm SEM. $\mathrm{n}=3$. 
A

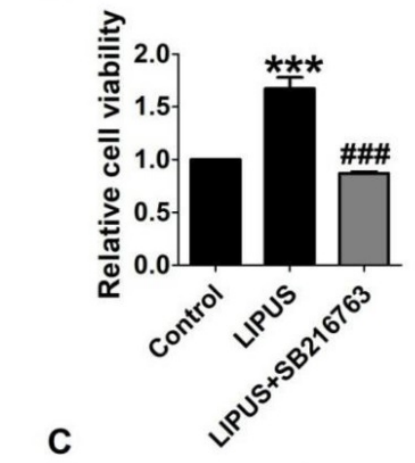

B

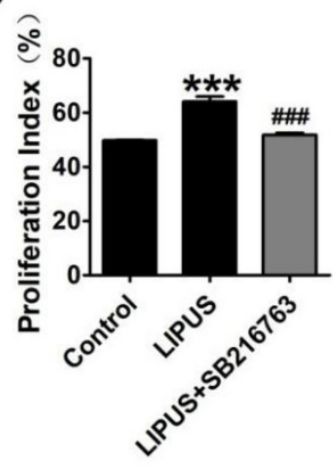

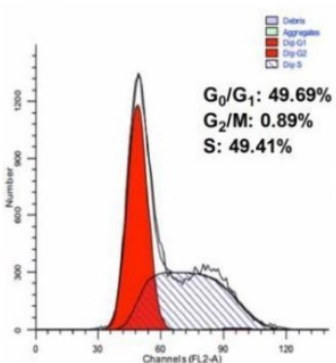

Control

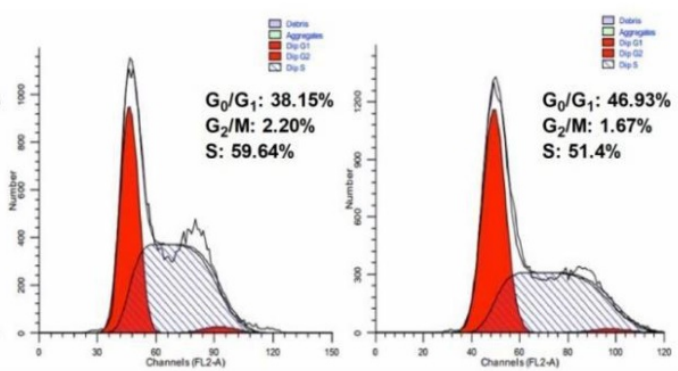

LIPUS

Figure 7. Effect on cell viability by inhibitor SB216763. (A). The cell viability was detected using MTT assay when the cells were co-treated with LIPUS and the GSK-3 $\beta$ inhibitor. (B). The cell viability was detected by flow cytometry when the cells were co-treated with LIPUS and the GSK-3 3 inhibitor. (C). The representative image of the flow cytometry detection.

A
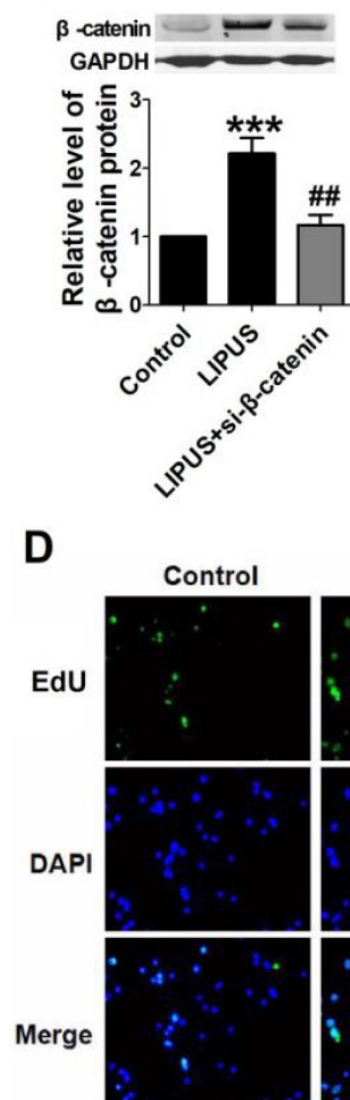

B

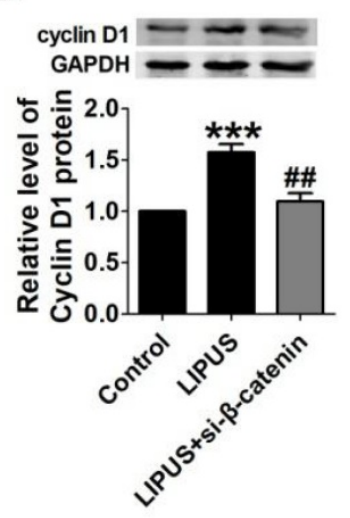

LIPUS
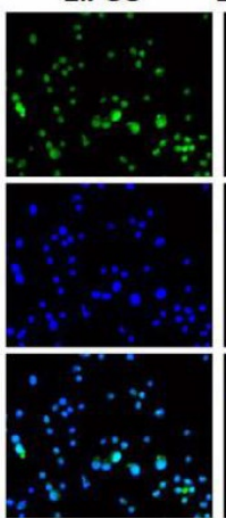
LIPUS+si- $\beta$-catenin

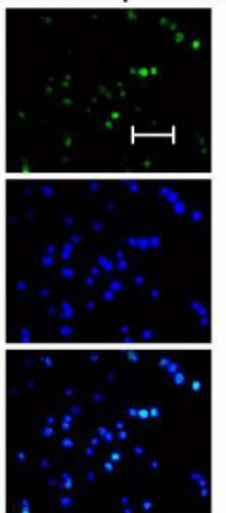

C

$\mathbf{E}$
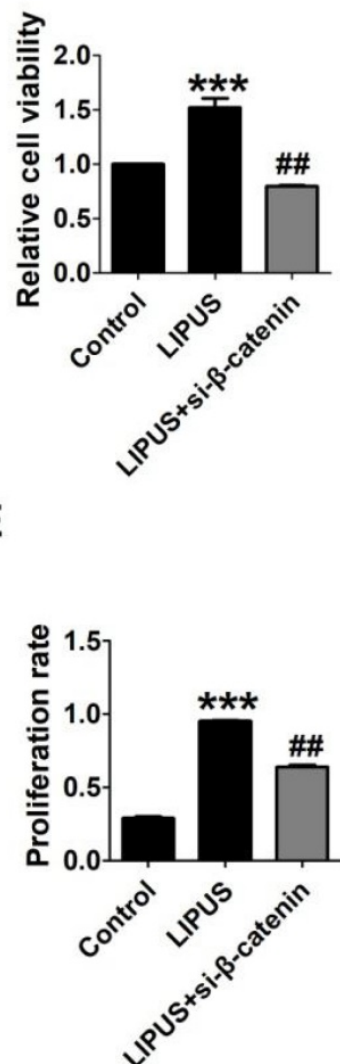

Figure 8. Results of blocking $\beta$-catenin. (A). The relative protein of $\beta$-catenin. (B). The relative protein of Cyclin DI. (C) The cell viability detected with MTT assay. ${ }^{* * *} p<0.001$ vs Control, \# $p<0.01$ vs LIPUS; mean \pm SEM. $n=3$. (D). The EdU staining of co-treated with $\beta$-catenin siRNA. (E). Quantification of the EdU staining. $* * *$ p $<0.001$ vs Control, \#\#p $<0.01$ vs LIPUS; mean \pm SEM. $n=3$. 
In 2002, Crisci and Ferreira revealed that Schwann cells were stimulated by low-intensity pulsed ultrasound with an electromicrographic morphologic study and proved that low-intensity pulsed ultrasound promoted the regeneration of the sciatic nerve after neurotomy in rats[31]. In addition, in 2009, Zhang et al revealed that LIPUS enhanced NT3 expression[44]. We assumed LIPUS may use two ways to improve peripheral nerve regeneration, including the up-regulation of a group of neurotrophic factors for the first type of peripheral nerve injury and the enhancement of the proliferation of Schwann cells and up-regulation of neurotrophic factors for the second type of peripheral nerve injury. Our results support our hypothesis, which could partly reveal the mechanism of the enhancement of nerve regeneration by LIPUS.

Low-intensity pulsed ultrasound gives cells a source of energy in the form of sound pressure. Some researches indicate that LIPUS promotes fracture healing and callus formation and promotes human bone marrow stromal cells and periosteal cells, which have biological effects[45, 46]. Therefore, the present study investigated whether LIPUS affects the viability and proliferation of cultured Schwann cells. The 27.5 $\mathrm{W} / \mathrm{cm}^{2}$ ultrasound intensity was used in our study. If the intensity was over $100 \mathrm{~mW} / \mathrm{cm}^{2}$, the Schwann cells underwent apoptosis, and if it was below 10 $\mathrm{mW} / \mathrm{cm}^{2}$, an enhanced effect was hardly found. The results proved our hypothesis. The MTT assay showed LIPUS promoted Schwann cell viability, and EdU staining showed LIPUS stimulated Schwann cell proliferation, which contributes to nerve regeneration improvement.

During the process of axon growth, Schwann cells provide neurotrophic factors for neurons, and some previous studies indicate that the promotion of the growth factors FGF and NGF or the neurotrophic factors BDNF and GNDF enhances the peripheral nerve injury recovery[47-49]. When the peripheral nerve was injured, the neurotrophic factors were expressed to attenuate the damage. NGF was the first identified neurotrophic factor and was purified in 1956, and it plays an important role in the development and maintenance of many neurons in both the central and peripheral nervous systems, promoting the injured peripheral nerve in adulthood. Recently, research devoted to promoting peripheral nerve regeneration by enhancing the NGF bioactivity was conducted[50]. FGF promotes peripheral nerve recovery by promoting axon outgrowth[51]. BDNF benefits Schwann cell regeneration and becomes a promising therapeutic molecule[52]. At the same time, GDNF promotes the precondition of Schwann cells after peripheral nerve injury[53]. Thus, it is necessary to explore the changes of neurotrophic factors after LIPUS treatment. Most of the neurotrophic factors are secreted proteins, and thus, we detected their expressions at the transcription level. In this study, we detected the mRNA level of some important growth factors and neurotrophic factors[54]. The western blot and real-time PCR assays showed that LIPUS elevated the expression of FGF, NGF, BDNF, and GDNF significantly, which enhanced axon growth.

To uncover the mechanism of the improved proliferation of Schwann cells by LIPUS, we studied the GSK-3 $\beta / \beta$-catenin/Cyclin D1 signaling pathway. The cell cycle progresses through four sequential phases, namely, the gap 1 (G1), synthesis (S), gap 2 (G2) and mitosis (M) phases. Passage through the cell cycle is strictly controlled by cyclin/CDK complexes. During the G1 phase, the cells need to decide whether to advance toward another division or withdraw from the cell cycle into the quiescence phase (G0) in response to the extracellular signals. Cyclin D1 acts as a mitogenic signal sensor and is expressed as a delayed-early response to many mitogenic signals, which forces cells to enter the proliferative cycle from the G0 phase[55, 56]. To explore the molecular mechanism of LIPUS stimulating Schwann cell proliferation, we detected the gene and protein expression of Cyclin D1, which participates in the regulation of CDKs[57]. The PCR, western blotting and immunofluorescence staining assays showed LIPUS elevated the activity of Cyclin D1 in Schwann cells.

The GSK-3 $\beta / \beta$-catenin/Cyclin D1 signaling pathway is an important regulatory signaling pathway that controls cell proliferation and differentiation[58]. Previous research reports that LIPUS affects GSK-3 $\beta$ activity through the PI3/Akt pathway in chondrocytes[59]. $\beta$-catenin is an intracellular regulatory transducer that is an important target of the Wnt signaling pathways. GSK-3 $\beta$ regulates $\beta$-catenin by regulating its nuclear accumulation, and through this pathway, GSK-3 $\beta$ regulates cell bio-functions, such as gene expression, protein synthesis, and cell viability[60,61]. As a result, to further explore the molecular mechanism and the relative signaling pathway, we studied the GSK-3 $\beta / \beta$-catenin/Cyclin D1 signaling pathway. The ratio of $p$-GSK-3 $\beta$ to GSK-3 $\beta$ showed that LIPUS increased the phosphorylation of GSK-3 $\beta$. The phosphorylation site decides the enzymatic activity of GSK-3 $\beta$, and in our study, the phosphorylation site is serine-9. We also used the selective inhibitor SB216763 to reverse the function of LIPUS. The results showed that LIPUS activated the GSK-3 $\beta / \beta$-catenin/Cyclin D1 signaling pathway, and at the same time, when we used the GSK-3 $\beta$ or $\beta$-catenin inhibitor co-treated with 
LIPUS, the elevated Cyclin D1 was restored, which indicated that LIPUS stimulated the Schwann cell proliferation via activating the GSK- $3 \beta / \beta$-catenin/ Cyclin D1 signaling pathway.

To conclude, our research revealed that LIPUS promoted Schwann cell viability and stimulated proliferation. LIPUS promoted the bio-function of secreted growth factors and neurotrophic factors, which help axon outgrowth in the lamina tubes when the nerve is regenerating. The GSK-3 $\beta / \beta$-catenin/ Cyclin D1 signaling pathway is the possible mechanism to explain the enhancement of nerve regeneration by LIPUS.

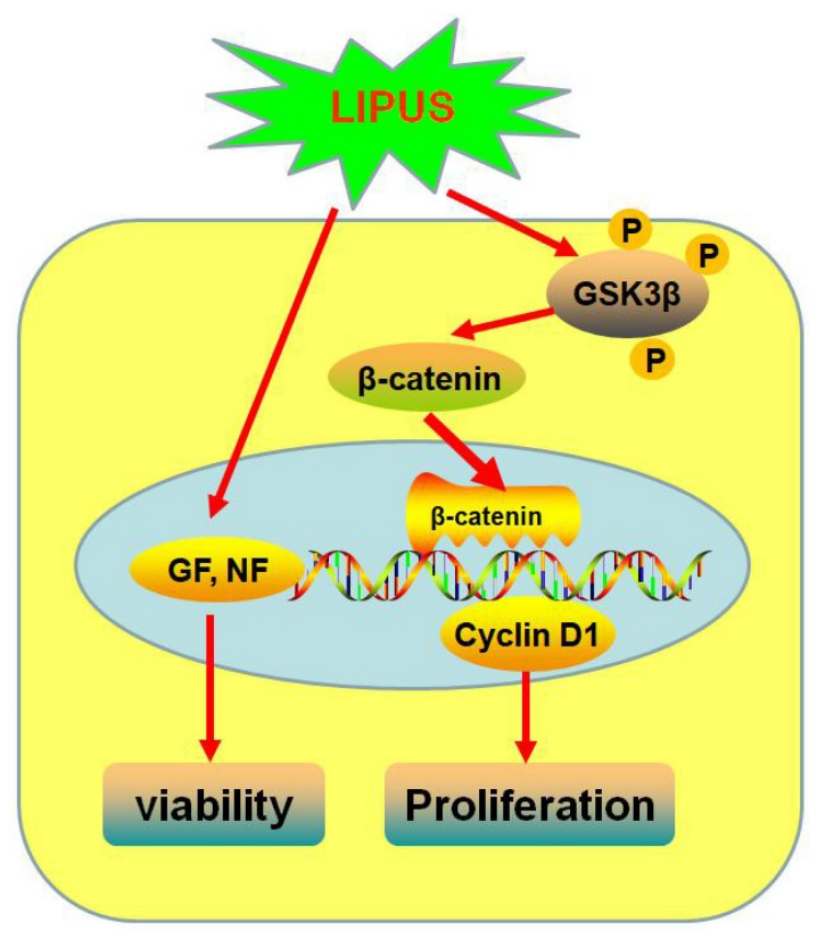

Figure 9. Schematic diagram of how LIPUS promotes the Schwann cell viability and proliferation signaling pathway. LIPUS significantly increased the expression of Cyclin DI by activating the GSK-3 $\beta / \beta$-catenin pathway.

\section{Abbreviations}

LIPUS: Low-intensity pulsed ultrasound; SCs: Schwann cells; FGF: Fibroblast Growth Factor; NGF: Nerve growth factor; BDNF: Brain-derived neurotrophic factor; GDNF: Glial cell-derived neurotrophic factor; CDK: cyclin-dependent kinase; EdU: 5Ethynyl-2'-deoxyuridine; GSK-3 $\beta$ : Glycogen synthase

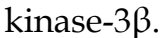

\section{Acknowledgements}

This work was supported by the Scientific Research Fund of Heilongjiang Provincial Education Department (NO: 12541468). The funders have no role in study design, data collection and analysis, decision to publish, or preparation of the manuscript.

\section{Competing Interests}

The authors have declared that no competing interest exists.

\section{References}

1. Raso VV, Barbieri $\mathrm{CH}$, Mazzer N, Fasan VS. Can therapeutic ultrasound influence the regeneration of peripheral nerves? J Neurosci Methods. 2005; 142: 185-92.

2. Mourad PD LD, Curra FP, Mohr BC, Andru KC, Avellino AM et al. Ultrasound accelerates functional recovery after peripheral nerve damage. Neurosurgery. 2001; 48: 1136-40.

3. Klein R. Cell sorting during regenerative tissue formation. Cell. 2010; 143: 32-4.

4. Cattin AL, Burden JJ, Van Emmenis L, Mackenzie FE, Hoving JJ, Garcia Calavia N, et al. Macrophage-Induced Blood Vessels Guide Schwann Cell-Mediated Regeneration of Peripheral Nerves. Cell. 2015; 162: 1127-39.

5. Monk KR, Feltri ML, Taveggia C. New insights on Schwann cell development. Glia. 2015; 63: 1376-93.

6. Romano CL RD, Logoluso N. Low-intensity pulsed ultrasound for the treatment of bone delayed union or nonunion: a review. Ultrasound Med Biol. 2009; 35: 529-36.

7. Ikeda K TT, Suzuki N, Shimada K, Otsuka K, Ito K. Effects of low-intensity pulsed ultrasound on the differentiation of $\mathrm{C} 2 \mathrm{C} 12$ cells. Life Sci. 2006; 79: 1936-43.

8. Hiyama A MJ, Iwashina T, Omi H, Watanabe T, Serigano K, Iwabuchi S, Sakai D. Synergistic Effect of Low-Intensity Pulsed Ultrasound on Growth Factor Stimulation of Nucleus Pulposus Cells. Journal of Orthopaedic Research. 2007; 25: 1574-81.

9. Takeuchi R RA, Komitsu N, Mikuni-Takagaki Y, Fukui A, et al. The role of microtubule dynamics in growth cone motility and axonal growth. J Cell Biol. 1995; 128: 139-55.

10. Hausner $\mathrm{T}$, Nogradi A. The use of shock waves in peripheral nerve regeneration: new perspectives? Int Rev Neurobiol. 2013; 109: 85-98.

11. Uddin SM, Richbourgh B, Ding Y, Hettinghouse A, Komatsu DE, Qin YX, et al. Chondro-protective effects of low intensity pulsed ultrasound. Osteoarthritis Cartilage. 2016; 24: 1989-1998.

12. Takeuchi R, Ryo A, Komitsu N, Mikuni-Takagaki Y, Fukui A, Takagi Y, et al. Low-intensity pulsed ultrasound activates the phosphatidylinositol 3 kinase/Akt pathway and stimulates the growth of chondrocytes in three-dimensional cultures: a basic science study. Arthritis Res Ther. 2008; 10: R77.

13. Kumagai K, Takeuchi R, Ishikawa H, Yamaguchi Y, Fujisawa T, Kuniya T, et al. Low-intensity pulsed ultrasound accelerates fracture healing by stimulation of recruitment of both local and circulating osteogenic progenitors. J Orthop Res. 2012; 30: 1516-21.

14. Lu H, Yang Y, Zeng C, Zhou J, Hu J, Xu D, et al. [Effect of low-intensity pulsed ultrasound stimulation on maturation of regenerate bone]. Zhong Nan Da Xue Xue Bao Yi Xue Ban. 2009; 34: 984-90.

15. Fumi Takahashi-Yanaga TS. GSK-3 $\beta$ regulates cyclin D1 expression: A new target for chemotherapy. Cell Signal. 2008; 20: 581-9.

16. Yao L, Cao J, Sun H, Guo A, Li A, Ben Z, et al. FBP1 and p27kip1 expression after sciatic nerve injury: implications for Schwann cells proliferation and differentiation. J Cell Biochem. 2014; 115: 130-40.

17. Zhang T, Hu Y, Ju J, Hou L, Li Z, Xiao D, et al. Downregulation of miR-522 suppresses proliferation and metastasis of non-small cell lung cancer cells by directly targeting DENN/MADD domain containing 2D. Sci Rep. 2016; 6: 19346.

18. Shen N, Li X, Zhou T, Bilal MU, Du N, Hu Y, et al. Shensong Yangxin Capsule prevents diabetic myocardial fibrosis by inhibiting TGF-beta1/Smad signaling. J Ethnopharmacol. 2014; 157: 161-70.

19. Zhang Y, Li X, Zhang Q, Li J, Ju J, Du N, et al. Berberine hydrochloride prevents postsurgery intestinal adhesion and inflammation in rats. J Pharmacol Exp Ther. 2014; 349: 417-26.

20. Zhang Y, Qin W, Zhang L, Wu X, Du N, Hu Y, et al. MicroRNA-26a prevents endothelial cell apoptosis by directly targeting TRPC6 in the setting of atherosclerosis. Sci Rep. 2015; 5: 9401.

21. Xu C, Hu Y, Hou L, Ju J, Li X, Du N, et al. beta-Blocker carvedilol protects cardiomyocytes against oxidative stress-induced apoptosis by up-regulating miR-133 expression. J Mol Cell Cardiol. 2014; 75: 111-21.

22. Li X, Du N, Zhang Q, Li J, Chen X, Liu X, et al. MicroRNA-30d regulates cardiomyocyte pyroptosis by directly targeting foxo3a in diabetic cardiomyopathy. Cell Death Dis. 2014; 5: e1479.

23. Zhou T, Meng X, Che H, Shen N, Xiao D, Song X, et al. Regulation of Insulin Resistance by Multiple MiRNAs via Targeting the GLUT4 Signalling Pathway. Cell Physiol Biochem. 2016; 38: 2063-78.

24. Qin W, Du N, Zhang L, Wu X, Hu Y, Li X, et al. Genistein alleviates pressure overload-induced cardiac dysfunction and interstitial fibrosis in mice. Br J Pharmacol. 2015; 172: 5559-72. 
25. Acosta CM, Cortes C, MacPhee H, Namaka MP. Exploring the role of nerve growth factor in multiple sclerosis: implications in myelin repair. CNS Neurol Disord Drug Targets. 2013; 12: 1242-56.

26. Gordon T. The role of neurotrophic factors in nerve regeneration. Neurosurg Focus. 2009; 26: E3.

27. Burnett MG ZE. Pathophysiology of peripheral nerve injury: A brief review. Neurosurg Focus. 2004; 16: 78-82

28. Parrinello S NI, Ribeiro S, Wingfield Digby P, Fedorova M, Parkinson DB, Doddrell RD, Nakayama M, Adams RH, Lloyd AC. EphB signaling directs peripheral nerve regeneration through Sox2-dependent Schwann cell sorting. Cell. 2010; 143: 145-55.

29. Battiston B GS, Ferrero M, Tos P. Nerve repair by means of tubulization: Literature review and personal clinical experience comparing biological and synthetic conduits for sensory nerve repair. Microsurgery. 2005; 25: 258-67.

30. Hong CZ LH, Yu J. Ultrasound thermotherapy effect on the recovery of nerve conduction in experimental compression neuropathy. Arch Phys Med Rehabil. 1988; 69: 410-4.

31. Crisci AR, Ferrira AL. Low-intensity pulsed ultrasound accelerates the regeneration of the sciatic nerve after neurotomy in rats. Ultrasound Med Biol. 2002; 28: 1135-41.

32. Lazar DA CF, Mohr B, McNutt LD, Kliot M, Mourad PD. Acceleration of recovery after injury to the peripheral nervous system using ultrasound and other therapeutic modalities. Neurosurg Clin N Am. 2001; 12: 353-7.

33. MADSEN PW Jr GJ. The effect of ultrasound on conduction velocity of peripheral nerve. Arch Phys Med Rehabil. 1961; 42: 645-9.

34. Chang CJ, Hsu SH. The effects of low-intensity ultrasound on peripheral nerve regeneration in poly(DL-lactic acid-co-glycolic acid) conduits seeded with Schwann cells. Ultrasound Med Biol. 2004; 30: 1079-84.

35. Paik NJ CS, Han TR. Ultrasound therapy facilitates the recovery of acute pressure-induced conduction block of the median nerve in rabbits. Muscle Nerve. 2002; 26: 356-61.

36. Chen ZL YW, Strickland S. Peripheral regeneration. Annu Rev Neurosci. 2007; 30: 209-33.

37. Vargas ME BB. Why isWallerian degeneration in the CNS so slow? Annu Rev Neurosci. 2007; 30: 153-79.

38. Allodi I UE, Navarro X. Specificity of peripheral nerve regeneration: Interactions at the axon level. Prog Neurobiol. 2012; 98: 16-37.

39. Fontana X HM, Da Costa C, Patodia S, Thei L, Makwana M, Spencer-Dene B, Latouche M, Mirsky R, Jessen KR, et al. c-Jun in Schwann cells promotes axonal regeneration and motoneuron survival via paracrine signaling. J Cell Biol. 2012; 198: 127-41.

40. Brushart TM AM, Griffin JW, Redett R, Hameed H, Zhou C, Wright M, Vyas A, Ho"ke A. Schwann cell phenotype is regulated by axon modality and centralperipheral location, and persists in vitro. Exp Neurol. 2013; 247: 272-81.

41. Hirata K KM. Myelin phagocytosis by macrophages and nonmacrophages during Wallerian degeneration. Microsc Res Tech. 2002; 57: 541-7.

42. S. R. Wallerian degeneration: The innateimmune response to traumatic nerve injury. J Neuroinflamm. 2011; 9: 109.

43. Vidal PM LE, Dooley D, Hendrix S. The role of "anti-inflammatory" cytokines in axon regeneration. Cytokine Growth Factor Rev. 2013; 24: 1-12.

44. Zhang H LX, Wan H, Li JH, Li JM. Effect of low-intensity pulsed ultrasound on the expression of neurotrophin-3 and brain-derived neurotrophic factor in cultured Schwann cells. Microsurgery. 2009; 29: 479-85.

45. Sena K, Angle SR, Kanaji A, Aher C, Karwo DG, Sumner DR, et al. Low-intensity pulsed ultrasound (LIPUS) and cell-to-cell communication in bone marrow stromal cells. Ultrasonics. 2011; 51: 639-44.

46. Uchida K, Urabe K, Naruse K, Mikuni-Takagaki Y, Inoue G, Takaso M. 5. Accelerated Fracture Healing Targeting Periosteal Cells: Possibility of Combined Therapy of Low-Intensity Pulsed Ultrasound (LIPUS), Bone Graft, and Growth Factor (bFGF). J Orthop Trauma. 2016; 30: S3.

47. Sabatier MJ, English AW. Pathways Mediating Activity-Induced Enhancement of Recovery from Peripheral Nerve Injury. Exerc Sport Sci Rev. 2015; 43: 163-71.

48. Qin J, Wang L, Sun Y, Sun X, Wen C, Shahmoradi M, et al. Concentrated growth factor increases Schwann cell proliferation and neurotrophic factor secretion and promotes functional nerve recovery in vivo. Int J Mol Med. 2016; 37: 493-500.

49. Costa GM, de Oliveira AP, Martinelli PM, Camargos ER, Arantes RM, de Almeida-Leite CM. Demyelination/remyelination and expression of interleukin-1beta, substance $\mathrm{P}$, nerve growth factor, and glial-derived neurotrophic factor during trigeminal neuropathic pain in rats. Neurosci Lett. 2016; 612: 210-8.

50. Li R, Wu J, Lin Z, Nangle MR, Li Y, Cai P, et al. Single injection of a novel nerve growth factor coacervate improves structural and functional regeneration after sciatic nerve injury in adult rats. Exp Neurol. 2016; 288: 1-10.

51. Matsumine H, Sasaki R, Tabata Y, Matsui M, Yamato M, Okano T, et al. Facial nerve regeneration using basic fibroblast growth factor-impregnated gelatin microspheres in a rat model. J Tissue Eng Regen Med. 2016; 10: E559-E67.

52. Yi S, Yuan Y, Chen Q, Wang X, Gong L, Liu J, et al. Regulation of Schwann cell proliferation and migration by miR-1 targeting brain-derived neurotrophic factor after peripheral nerve injury. Sci Rep. 2016; 6: 29121.

53. Marquardt LM, Sakiyama-Elbert SE. GDNF preconditioning can overcome Schwann cell phenotypic memory. Exp Neurol. 2015; 265: 1-7.

54. Aghayan HR, Arjmand B, Norouzi-Javidan A, Saberi H, Soleimani M, Tavakoli SA, et al. Clinical grade cultivation of human Schwann cell, by the using of human autologous serum instead of fetal bovine serum and without growth factors. Cell Tissue Bank. 2012; 13: 281-5.

55. CJ S. D-type cyclins. Trends Biochem Sci. 1995; 20: 187-90.

56. CJ S. Cancer cell cycles. Science. 1996; 274: 1672-7.

57. Orlando S, Gallastegui E, Besson A, Abril G, Aligue R, Pujol MJ, et al. p27Kip1 and p21Cip1 collaborate in the regulation of transcription by recruiting cyclin-Cdk complexes on the promoters of target genes. Nucleic Acids Res. 2015; 43: 6860-73.

58. Hui J, Zhang J, Kim H, Tong C, Ying Q, Li Z, et al. Fluoxetine regulates neurogenesis in vitro through modulation of GSK-3beta/beta-catenin signaling. Int J Neuropsychopharmacol. 2015; 18: 1-12.

59. Takeuchi R RA, Komitsu N, Mikuni-Takagaki Y, Fukui A, Takagi Y, Shiraishi T, Morishita S, Yamazaki Y, Kumagai K, Aoki I, Saito T. Low-intensity pulsed ultrasound activates the phosphatidylinositol 3 kinase/akt pathway and stimulates the growth of chondrocytes in three-dimensional cultures: A basic science study. Arthritis Res Ther. 2008; 10: R77.

60. Oloumi A, Syam S, Dedhar S. Modulation of Wnt3a-mediated nuclear beta-catenin accumulation and activation by integrin-linked kinase in mammalian cells. Oncogene. 2006; 25: 7747-57.

61. Zhang Y, Li X, Li J, Zhang Q, Chen X, Liu X, et al. The anti-hyperglycemic efficacy of a lipid-lowering drug Daming capsule and the underlying signaling mechanisms in a rat model of diabetes mellitus. Sci Rep. 2016; 6: 34284 . 